JPE 11-5-10

\title{
A Hybrid DTC-DSC Drive for High Performance Induction Motor Control
}

\author{
Auzani Jidin*, Nik Rumzi Nik Idris**, Abdul Halim Mohamed Yatim***, Tole Sutikno***, and Malik E. Elbuluk ${ }^{\dagger}$ \\ * Dept. of Power Electronics and Drives, FKE, Universiti Teknikal Malaysia, Melaka, Skudai, Malaysia \\ ** Dept. of Energy Conversion, FKE, Universiti Teknologi Malaysia, Johor, Skudai, Malaysia \\ *** Dept. of Electrical Engineering, Universitas Ahmad Dahlan, Yogyakarta, Indonesia \\ ${ }^{\dagger}$ Dept. of Electrical Engineering, University of Akron, Akron, Ohio, USA
}

\begin{abstract}
This paper describes a hybrid induction motor drive system incorporating DTC-hysteresis and Direct Self Control (DSC) schemes to achieve excellent dynamic performance. The control scheme is switched from a circular to a hexagonal flux locus whenever a dynamic condition is encountered. On the other hand, when the motor operates under steady state conditions, a circular flux locus is used. Without major modifications to the simple structure of a basic DTC, hexagonal flux locus operation is established by modifying the flux error status, before it is fed to the look-up table. The feasibility of the proposed hybrid scheme to achieve excellent control performance is verified by experimental results.
\end{abstract}

Key Words: Direct Self Control, Direct Torque Control, Hexagonal flux locus, Induction Motor

\section{INTRODUCTION}

In recent years, the Direct Torque Control (DTC) scheme for induction motor drives has received an enormous amount of attention in industrial motor drive applications. The main reason for its popularity is due to its simple structure, especially when compared with the field-oriented control (FOC) scheme, which was introduced a decade earlier. Since DTC was first introduced [1], several variations on its original structure have been proposed to overcome the inherent disadvantages in any hysteresis-based controller such as, a variable switching frequency, a high sampling requirement for digital implementation and a high torque ripple [2]-[9].

The most popular variation on the DTC of induction motor drives is one that is based on space vector modulation (SVM), which is normally referred to as DTC-SVM [10]-[16]. Continuous improvements utilizing this technique have gained much momentum in order to facilitate DTC to operate in overmodulation mode to fully utilize the available DC voltage. In DTCSVM it is possible to operate in overmodulation mode which is defined based on the reference voltage vectors generated

Manuscript received Oct. 20, 2010; revised May 20, 2011

Recommended for publication by Associate Editor Kyeong-Hwa Kim

$\dagger$ Corresponding Author: melbuluk@uakron.edu

Tel: +330-972-6531, Fax: +330-972-6487, University of Akron

* Dept. of Power Electronics and Drives, FKE, Universiti Teknikal Malaysia Melaka, Malaysia

** Dept. of Energy Conversion, FKE, Universiti Teknologi Malaysia, Skudai, Malaysia

*** Dept. of Electrical Engineering, Universitas Ahmad Dahlan, Indonesia by controller. However, in DTC-hysteresis based control, this is not possible simply because there is no reference voltage available.

In SVM, overmodulation mode starts whenever the reference voltage vector goes beyond the hexagonal boundary of the voltage vector plane. It is well known that the operation of overmodulation is very important in many electric drive applications in order to improve the power output and dynamic performance. In fact, the fastest torque dynamic and the high capability of the torque in a flux weakening region can be achieved if the stator voltage is able to operate in sixstep mode. For these reasons, many researchers had shown significant interest in developing methods for estimating the maximum possible reference voltage during torque dynamic [15]-[17]. For examples, [16] utilized predictive control of the stator flux error vector to estimate the reference voltage and [15] used dead-beat control with several complicated equations to generate the reference voltage in real-time. Among the various schemes proposed, only [16] and [18] can achieve fast torque dynamic control and maximum torque capability in the flux weakening region with six-step voltage operation. Unfortunately, all of the proposed methods [15]-[17] increases the complexity of the DTC control structure and deviates from the simple drive structure as originally proposed in [1].

This paper proposes a simple way to achieve a fast torque dynamic and a high torque capability by using a hybrid scheme. The working principle of the proposed hybrid scheme is to switch the DTC operation to DSC operation when a dynamic condition encountered. The main benefit of the proposed hybrid scheme is its simplicity since the merits of 


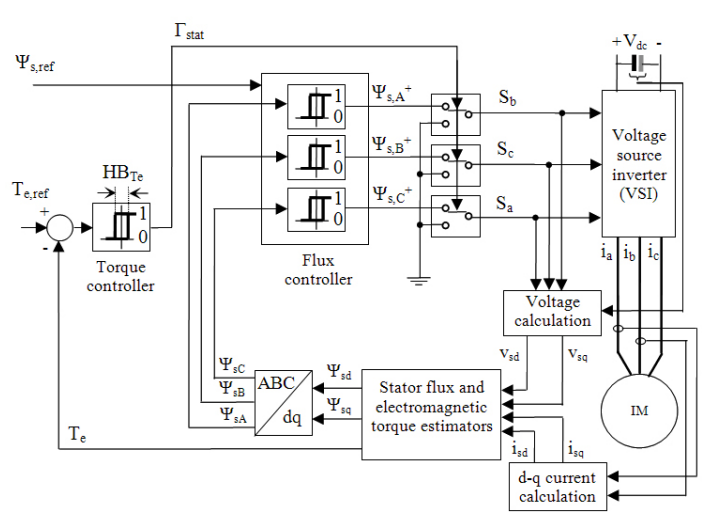

Fig. 1. Structure of Direct Self Control based induction machine.

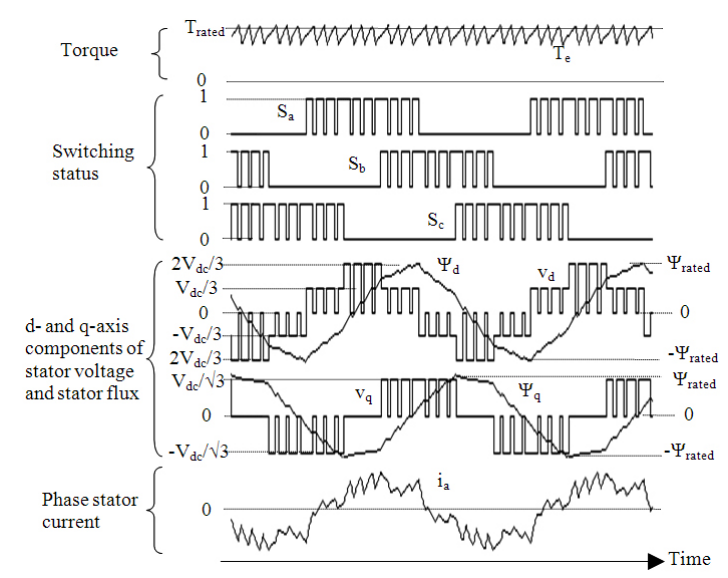

Fig. 2. Typical waveforms in direct self control operation.

each scheme can be performed without the need for major modifications to the structure of basic DTC. In this paper, the principle of basic DTC will not be explained since this scheme is well-known and has been widely discussed in many technical papers. However, the principle of direct self control (DSC), which has similar operation to the hexagonal flux control in the hybrid scheme, will be briefly explained in Section II. In Section III of this paper, a detail explanation of the construction and operation of the proposed hybrid scheme will be presented. Section IV demonstrates the high performance of the hybrid scheme. Section V presents both its implementation and experimental results. Finally, a conclusion is given in Section VI.

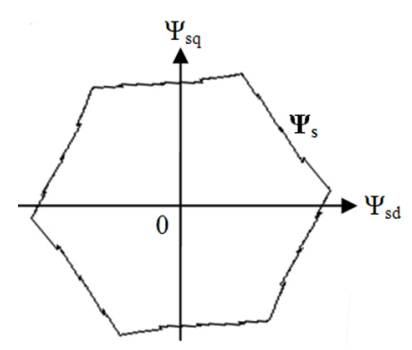

(a)

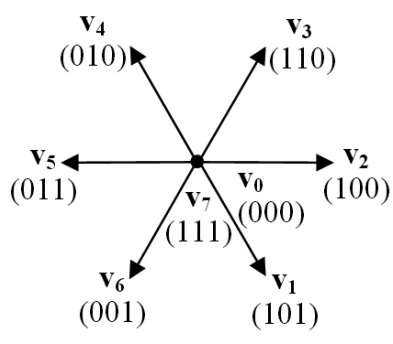

(b)
Fig. 3. Control of flux vector to a hexagonal shape with the appropriate voltage vectors. (a) Stator flux plane (b) Voltage vector plane.

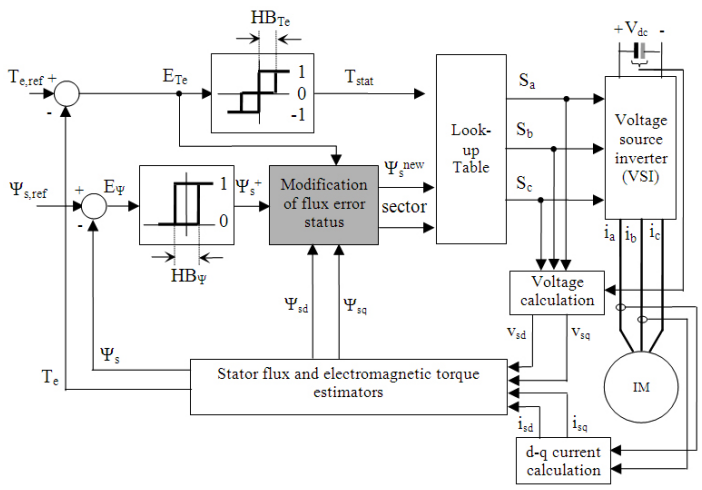

Fig. 4. The structure of hybrid induction motor drive with the proposed block of 'modification of flux error status' (to perform DSC operation).

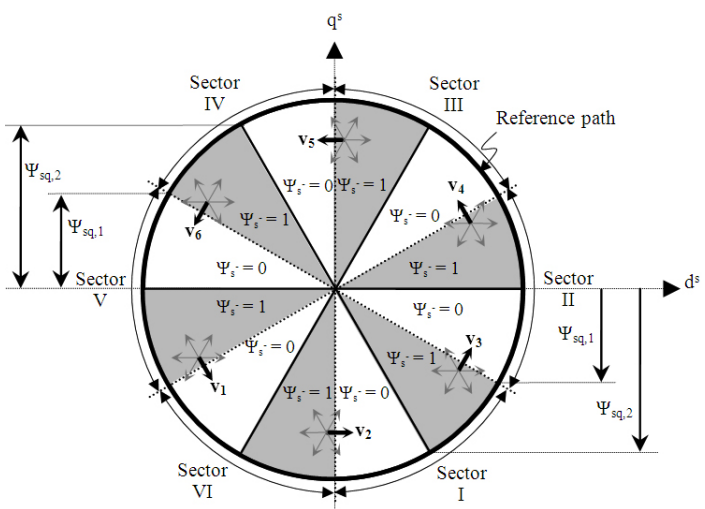

Fig. 5. The appropriate digital outputs in modified flux error status $\Psi_{s^{-}}$ correspond to the optimized voltage vectors for every sub sector in each sector.

\section{Basic Principle of Direct Self Control}

The control structure of the direct self control (DSC) proposed by M. Depenbrock [18] is depicted in Fig. 1. Unlike DTC, DSC does not require sector identification and a lookup table for selecting the voltage vector. Moreover, it operates on the basis of hexagonal flux control where the active voltage vectors $\left(\mathbf{v}_{1}, \mathbf{v}_{2}, \mathbf{v}_{3}, \ldots, \mathbf{v}_{6}\right)$ used to form the hexagonal shape are determined according to the appropriate digitized outputs $\left(\Psi_{s, A^{+}}, \Psi_{s, B}{ }^{+}\right.$and $\left.\Psi_{s, C}{ }^{+}\right)$. The digitized outputs generated from three units of hysteresis comparators are based on the command of the stator flux $\left(\Psi_{s, r e f}\right)$ and the phase flux components $\left(\Psi_{s A}, \Psi_{s B}\right.$ and $\left.\Psi_{s C}\right)$. Meanwhile, the torque hysteresis comparator produces the signal that determines zero voltage vector $\left(\mathbf{v}_{0}\right.$ or $\left.\mathbf{v}_{7}\right)$ when the output torque satisfies its demand $\left(\Gamma_{\text {stat }}=0\right)$. For a constant flux region, the generation of the switching states $\left(\mathrm{S}_{a} \mathrm{~S}_{b} \mathrm{~S}_{c}\right)$ which determine the voltage vectors can be described by the following equations:

$$
\begin{gathered}
S_{\mathrm{a}}=\Psi_{\mathrm{s}, \mathrm{A}}^{+}, \mathrm{S}_{\mathrm{b}}=\Psi_{\mathrm{s}, \mathrm{B}}^{+}, \mathrm{S}_{\mathrm{c}}=\Psi_{\mathrm{s}, \mathrm{C}}^{+} \text {for } \Gamma_{\text {stat }}=1 \\
\mathrm{~S}_{\mathrm{a}}=0, \mathrm{~S}_{\mathrm{b}}=0, \mathrm{~S}_{\mathrm{c}}=0 \quad \text { for } \Gamma_{\text {stat }}=0 .
\end{gathered}
$$

Fig. 2 illustrates typical waveforms in DSC when the torque and the flux are operating under rated conditions. The generation of switching status is based on (1) and (2), as described above. As can be seen, the finite slope of the flux components in Fig. 2, was created when the active voltage vectors employed, which in turn results in a hexagonal flux locus as depicted in Fig. 3(a). Fig. 3(b) shows the switching states for each voltage vector (e.g. $\left.\mathbf{v}_{n}\left(\mathrm{~S}_{a} \mathrm{~S}_{b} \mathrm{~S}_{c}\right)=\mathbf{v}_{4}(010)\right)$ 


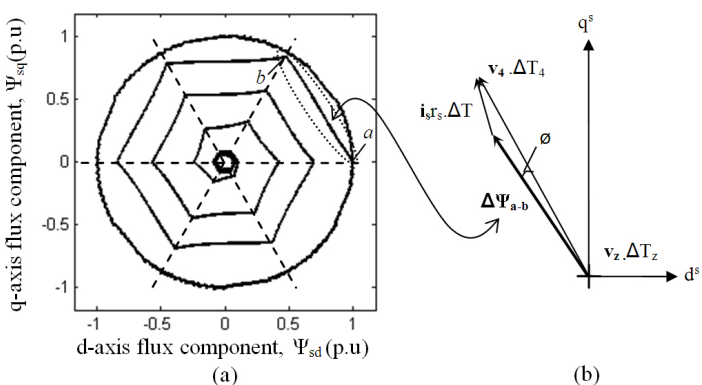

(a)

Fig. 6. Effect of ohmic drop vector to the motion of flux vector when the appropriate voltage vector is applied. (a) Locus of flux (b) voltage vector.

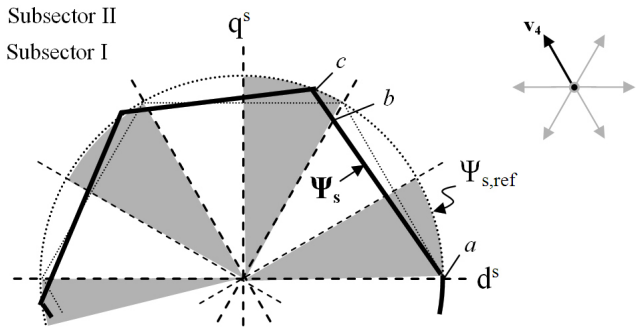

Fig. 7. Flux keeps the increase as it enters to sub sector 2 until it reaches to the point $c$. (i.e. path $b-c$ ) with the $\Psi_{\mathrm{s}, \bmod ^{-}}=0$.

which is useful for identifying the application of the voltage vector (by examining the switching pattern in Fig. 2). The use of the zero voltage vector, which represents the satisfaction of the torque demand, is ideally halting the flux vector, thus it will not affect the flux trajectory.

It is well known that DSC is suitable for high power applications since it offers a lower switching frequency (for high power efficiency) and is superior in torque dynamic response. The lower switching frequency corresponds to a lower numbers of commutation in the switching states (i.e. the switching state $\mathrm{S}_{a}$ only commutates for a half cycle of the flux), which decreases as the hysteresis band of the torque increases. However, this scheme produces a high current total harmonic distortions (THD) even when operating in steady state conditions.

\section{The Proposed Hybrid Scheme}

The hybrid scheme is proposed to facilitate operation of the conventional DTC scheme in dual-mode flux control. This section will discuss how the hexagonal flux locus is obtained with minor modifications to the conventional DTC control structure. The mechanisms and conditions for the transitions between a circular and a hexagonal stator flux locus will also be presented.

\section{A. Hexagonal Flux Control in the Proposed Hybrid Scheme}

In general, it is possible to establish hexagonal stator flux locus control using the conventional DTC control structure. To accomplish this one has to modify the lookup table as well as redefine the stator flux sector. This means that it is possible to interchangeably operate between DTC and DSC using the same control hardware. However, this method is not suitable, especially when frequent switching and smooth transitions between the two schemes are required. To overcome this, the proposed hybrid scheme in this paper uses a simple

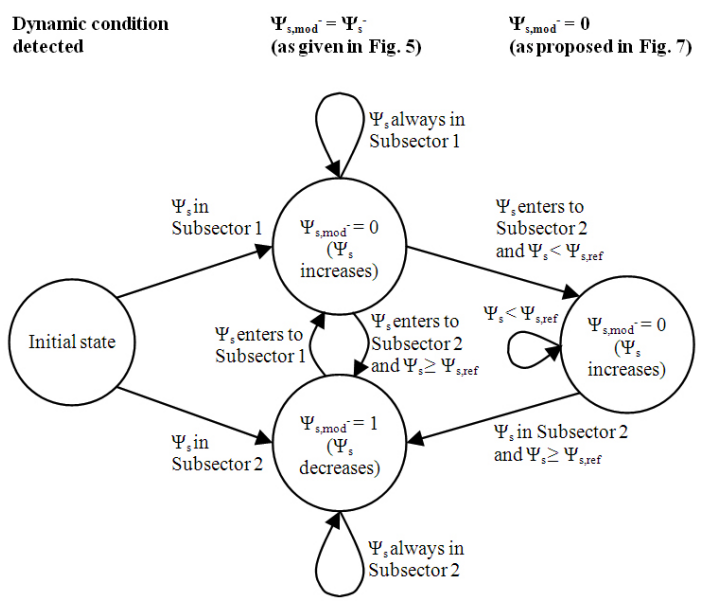

Fig. 8. State diagram of finite state machine that establishes the modified flux error status $\left(\Psi_{r m s, m^{-}}\right)$to perform the proper hexagonal operation.

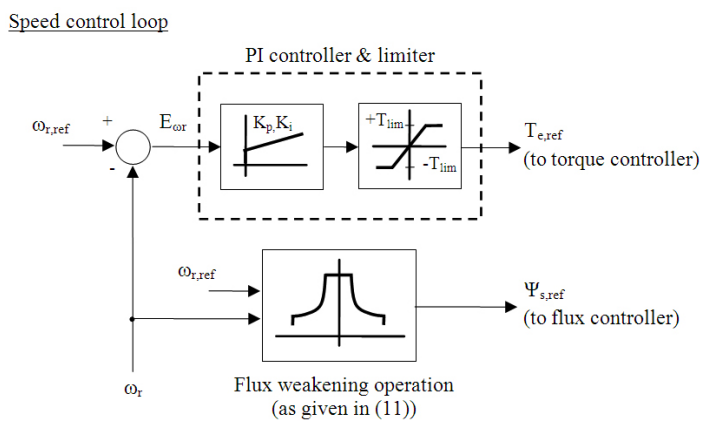

Fig. 9. Computation of references of torque and flux in the proposed hybrid scheme.

technique to establish a hexagonal flux locus without the need to modify the lookup table and redefine the stator flux sector. Fig. 4 shows the control structure of the hybrid DTC, which is similar to the conventional DTC control structure, but with an inclusion of the 'modification of flux error status' block. When the 'modification of flux error status' block is activated, the output of the hysteresis controller (i.e. the input to the block), $\Psi^{+}$is modified to $\Psi_{s}{ }^{n e w}$ and the stator flux locus will be transformed to hexagonal. Otherwise, the block is not activated, $\Psi_{S}^{\text {new }}=\Psi^{+}$and the flux locus remains circular. The activation of the block is performed whenever a dynamic condition is encountered and this is discussed further in part $\mathrm{B}$ of this section.

As can be seen in Fig. 5, each sector in the stator flux plane is divided into two sub sectors; subsector I (unshaded area) and subsector II (shaded area). The border of the sectors and the subsectors can be easily calculated using the threshold values of $\Psi_{s, q}{ }^{s}$, denoted as $\Psi_{s q, 1}$ and $\Psi_{s q, 2}$, which are given as:

$$
\begin{aligned}
& \Psi_{\mathrm{sq}, 1}=\Psi_{\mathrm{s}, \mathrm{d}}^{\mathrm{s}} \cdot \tan (\pi / 6) \\
& \Psi_{\mathrm{sq}, 2}=\Psi_{\mathrm{s}, \mathrm{d}}^{\mathrm{s}} \cdot \tan (\pi / 3) .
\end{aligned}
$$

In this way, the generation of the appropriate flux error status and the detection of the six sectors, as required in conventional DTC operation, can be merged into the same block. Hence, the DTC algorithm, including the modification of the flux error status can be simplified to retain the simple algorithm. 


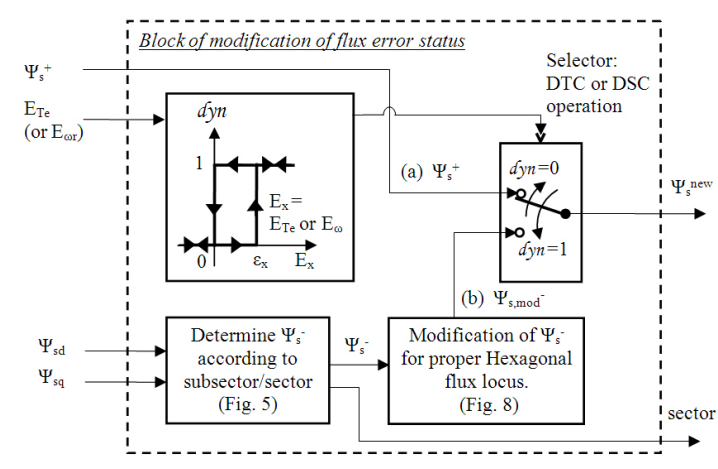

Fig. 10. The selection of flux error status in the block of modification of flux error status. (a) Original flux error status $\Psi_{s}^{+}$for circular locus. (b) Modified flux error status $\Psi_{\mathrm{s}, \mathrm{mod}^{-}}$for hexagonal locus.

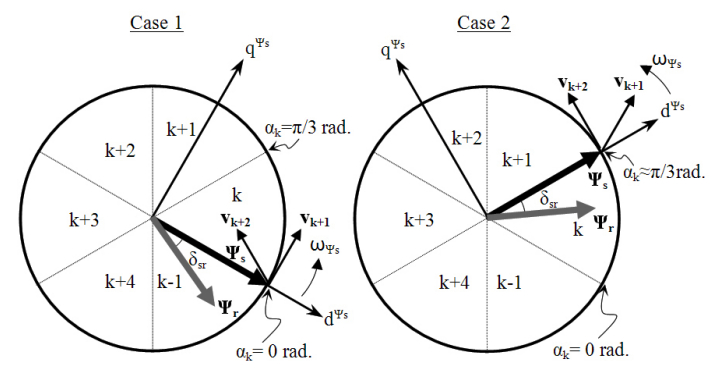

(a)

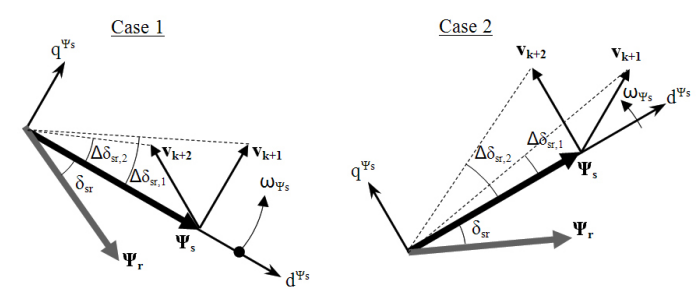

(b)

Fig. 11. Effects of selecting different switching under dynamic condition. (a) Stator voltage vector in stator flux. (b) Comparison of the load angle, $\delta_{\text {sr }}$ generated by the same magnitude of appropriate voltage vectors.

Ideally, to produce a hexagonal flux locus, the stator flux error has to be set according to $\Psi^{-}$as illustrated in Fig. 5. For example, the voltage vector $\mathbf{v}_{4}$ should be selected whenever the flux is located between the middle of Sector II and the middle of Sector III. From the middle of Sector III to the middle of Sector IV, the voltage vector $\mathbf{v}_{5}$ should be chosen, and so forth. However, in practice the use of $\Psi_{s}^{-}$to attain the desired hexagonal flux locus as described above will not work. The locus of the flux may "shrink" as the speed increases although the motor should be operated in a constant flux region. This problem is illustrated by a simulation result as shown in the Fig. 6(a). In the simulation, the transition from a circular to a hexagonal locus starts at $a$ (the middle of Sector II). At point $b$ (the middle of Sector III), the flux fails to reach its reference. The reduction will continue as the flux moves from one vertex to another, and eventually, the size of the hexagonal is reduced. The shrinking of the hexagonal stator flux is due to the effect of the ohmic voltage drop that causes the trajectory of the flux motion to not align with the direction of the applied voltage vector. To explain this, consider the motion of the flux from point $a$ (the middle of sector II) to point $b$ (the middle

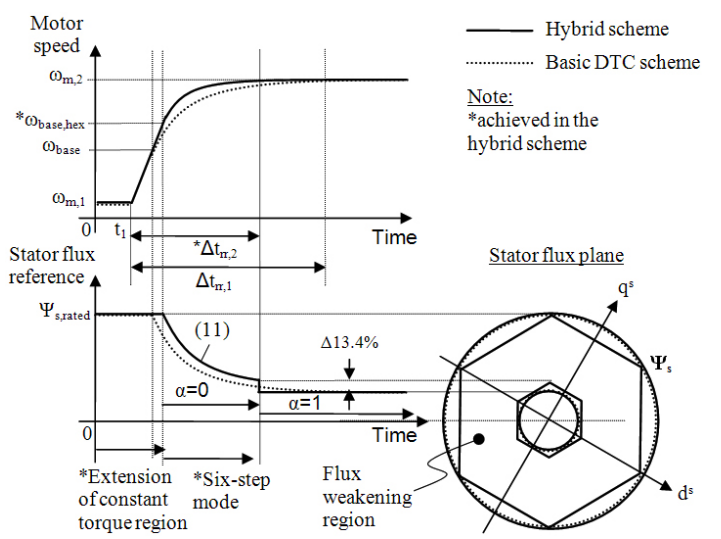

Fig. 12. More rapid motor acceleration achieved with the hybrid scheme when a step change of reference speed applied at time $t_{1}$.

of sector III) as the vector $\mathbf{v}_{4}$ employed. A phasor diagram of the related component vectors (i.e. change of the flux vector, applied voltage vector and ohmic voltage drop) is drawn based on the stator voltage equation, as depicted in Fig. 6(b). In this case the change of the flux vector from $a$ to $b$ can be expressed as:

$$
\Delta \Psi_{a-b}=v_{z} \cdot \Delta \mathrm{T}_{\mathrm{z}}+v_{4} \cdot \Delta \mathrm{T}_{4}-i_{s} \mathrm{r}_{\mathrm{S}} \cdot \Delta \mathrm{T}
$$

where $\mathbf{v}_{z}$ is the zero voltage vector (this can be either $\mathbf{v}_{0}$ or $\mathbf{v}_{7}$ ), and $\Delta \mathrm{T}_{z}$ and $\Delta \mathrm{T}_{4}$ are the respective switching periods of $\mathbf{v}_{z}$ and $\mathbf{v}_{4}$. Hence, the time taken for the flux vector to travel from $a$ to $b$ is given by:

$$
\Delta \mathrm{T}=\Delta \mathrm{T}_{\mathrm{z}}+\Delta \mathrm{T}_{4} .
$$

According to (5) and (6), the effect of the ohmic voltage drop $\left(\mathbf{i}_{s} r_{s}\right)$, which causes the reduction of the flux, is affected by $\Delta \mathrm{T}$, which is the summation of $\mathbf{v}_{z}$ and $\mathbf{v}_{4}$. This indicates that, the operation described above (the selection of $\Psi_{s}{ }^{-}$as given in Fig. 5) can still become problematic even in the absence of the zero voltage vector. In fact, no matter how small the deviation angle between the vectors of the applied voltage and the flux change $(\phi)$, the locus of the hexagonal will still shrink (gradually) as the flux moves from one vertex to another.

It is desirable to keep the size of the hexagonal locus such that all six of the vertices are located on the circular reference in order to achieve proper torque control and hence maximum torque capability. The problem indicated in Fig. 6(a) can be solved if the applied active voltage for increasing the flux magnitude in subsector I is maintained until the flux reaches the circular reference, as illustrated in Fig. 7. In this case, the flux travels from point $a$ to the point $b$ by applying the flux error status as given in Fig. 5 (i.e. $\Psi_{s, \text { mod }}{ }^{-}=\Psi_{s}{ }^{-}$). However, the flux error status, as given in Fig. 5, is modified to 0 (i.e. $\Psi_{s, \text { mod }}{ }^{-}=0$ ) as the flux enters subsector II, until the flux reaches point $c$. The generation of the modified flux error status $\Psi_{s, \text { mod }}{ }^{-}$to overcome the problem can be described by a state diagram of a finite state machine as shown in Fig. 8.

\section{B. Definitions of the dynamic conditions.}

The proposed hybrid scheme will change the control of the circular flux locus to hexagonal when a dynamic condition is 

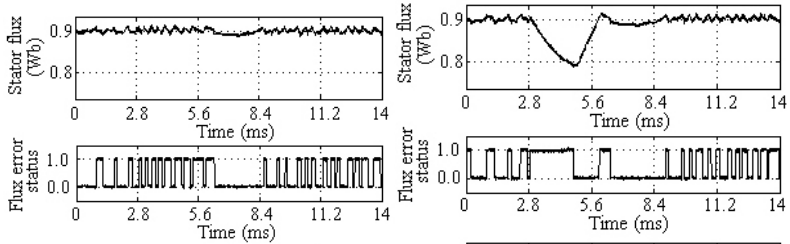

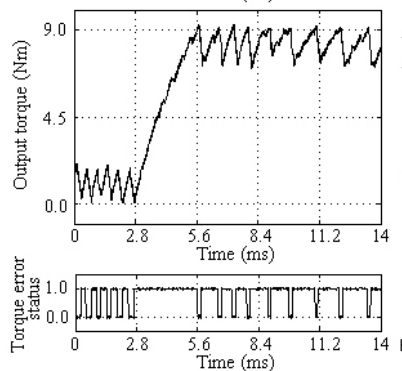

(a)

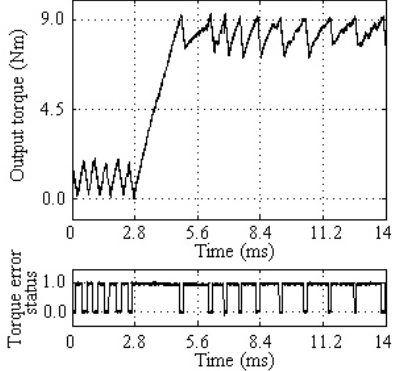

(b)
Fig. 13. Comparison by experimentation of dynamic torque performance obtained in (a) the basic DTC and (b) the hybrid scheme, when a dynamic torque control occurs at the middle of flux sector II.

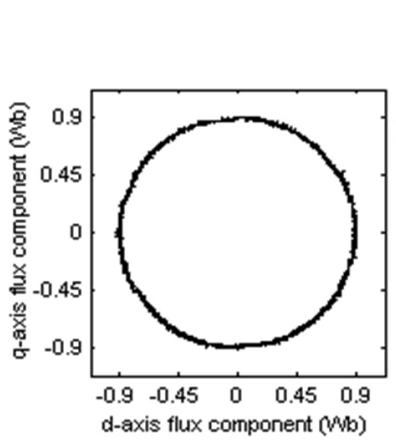

(a)

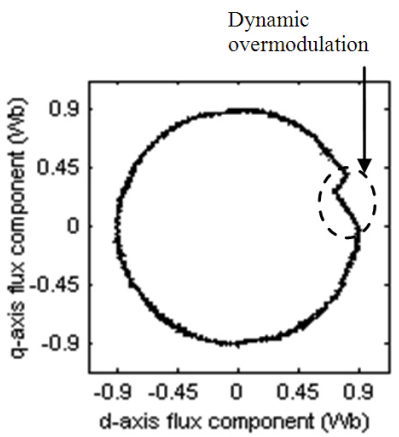

(b)
Fig. 14. Comparison of stator flux locus obtained between (a) basic DTC and (b) the proposed hybrid drive (for one complete flux wave cycle) when a torque dynamic condition occurs at the middle of sector II.

encountered. By doing so, the stator voltage will change to a six-step and hence the available DC voltage will be fully utilized. As will be discussed later, this will results in a better torque response and a faster motor acceleration. In this paper, two dynamic conditions are defined as follows:

1) Torque dynamic condition: this condition is detected when the torque error $\mathrm{E}_{T e}$ is greater than twice the hysteresis band of the torque controller, $\mathrm{HB}_{T e}$. It is asserted that the definition of the torque dynamic used in the proposed method is straightforward enough to detect any sudden large change in the torque reference. In this case, the hybrid scheme works with the torque control loop as depicted in Fig. 4.

2) Motor acceleration condition: this condition is detected when the speed error $\mathrm{E}_{\omega}$ is greater than $5 \mathrm{rad} . / \mathrm{s}$. In this case, the hybrid scheme works with the speed control loop, where the references of the torque and the flux are generated as depicted in Fig. 9.

On the other hand, the proposed hybrid scheme will change the control of the flux from the hexagonal to the circular locus when the error of the torque $\mathrm{E}_{T e}$ (in the case of the torque

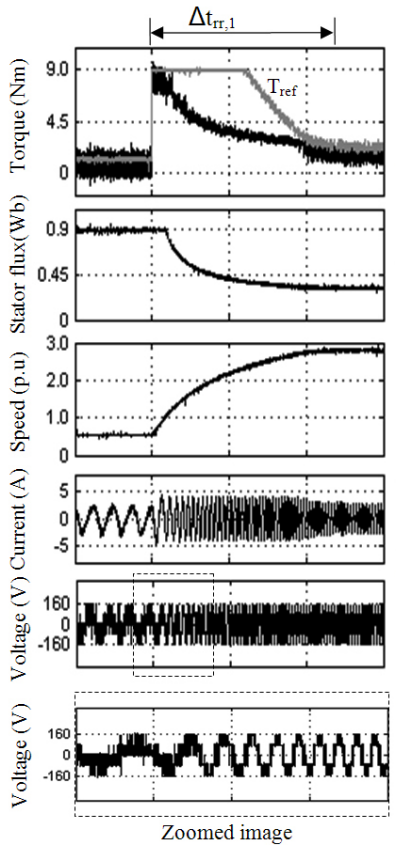

(a)

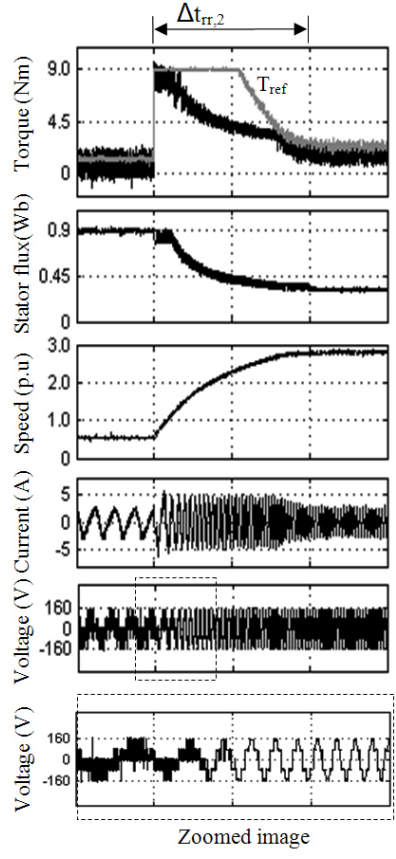

(b)
Fig. 15. Comparison by experimentation of capability of torque obtained in (a) the basic DTC and (b) the proposed hybrid drive (Time scale: $400 \mathrm{~ms} / \mathrm{div}$.).

control loop) or the speed $\mathrm{E}_{\omega}$ (in the case of the speed control loop) reduces to zero. This means that the proposed hybrid scheme will be operated using the conventional DTC scheme when the motor runs in steady state conditions. Therefore, the current distortion due to the hexagonal flux shape (as explained in Section II) will only occur during torque transient or motor acceleration, which happen in a relatively short period of time.

Fig. 10 illustrates the selection of flux error status in the block of modification of flux error status. The detection of the dynamic condition as explained earlier is determined using a two-level hysteresis comparator. For the torque dynamic condition (or the motor acceleration condition), the comparator output signal denoted as $d y n$ will be equal to 1 when the error of torque $\mathrm{E}_{x}=\mathrm{E}_{T e}$ (or speed $\mathrm{E}_{x}=\mathrm{E}_{\omega}$ ) is greater than $\varepsilon_{x}=2 \mathrm{HB}_{T e}$ (or $\varepsilon_{x}=5 \mathrm{rad} . / \mathrm{s}$ ). If not, the signal $d y n$ will be equal to 0 when the torque (or speed) error is reduced to zero. The selector will pick up the modified flux error status $\Psi_{s, \text { mod }}{ }^{-}$as $\Psi_{s}{ }^{\text {new }}$, when $d y n=1$, otherwise it will pick up the original flux error status $\Psi_{s}{ }^{+}$as $\Psi_{s}$ new. Then, the new flux error status $\Psi_{s}{ }^{\text {new }}$, along with the sector information, is fed to the lookup table to determine the most optimized voltages for excellent performance of induction machine drives.

\section{Performance of The Hybrid DTC}

This section explains on how the operation of a hexagonal flux locus utilizing the hybrid scheme can achieve excellent dynamic performance. For ease of explanation, the reasons will be given according to the conditions of the dynamic.

\section{A. Fast torque dynamic control}

It is well known that, the original DTC scheme proposed by Takahashi [1] offers fast instantaneous torque and flux control 


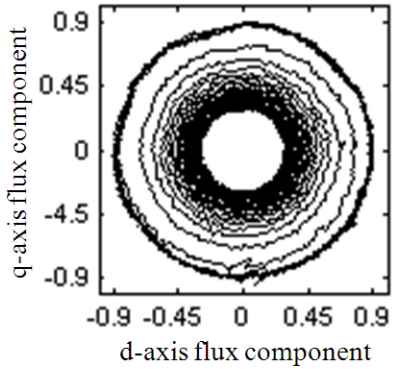

(a)

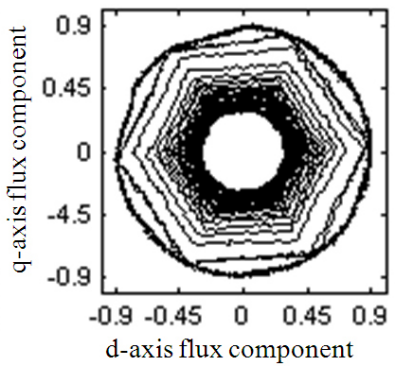

(b)
Fig. 16. Comparison of stator flux locus obtained in (a) the basic DTC and (b) the proposed hybrid DTC drive.

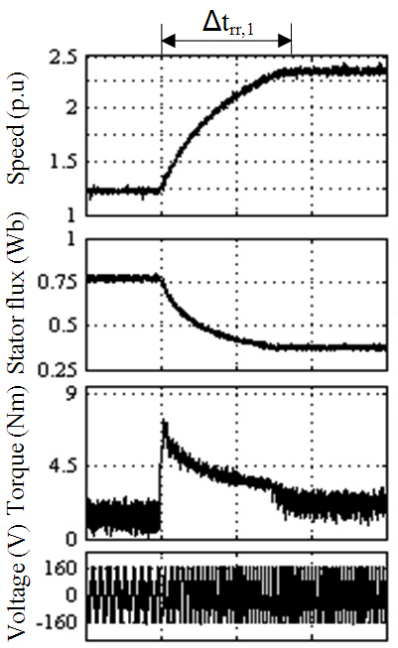

(a)

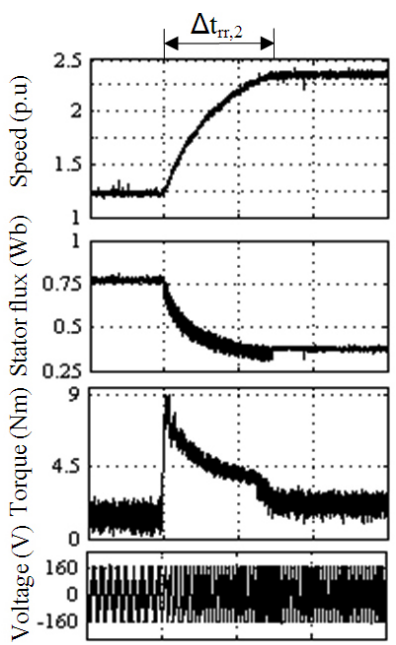

(b)
Fig. 17. Comparison by experimentation of torque capability in flux weakening region obtained in (a) the basic DTC and (b) the proposed hybrid drive (Time scale: $400 \mathrm{~ms} /$ div. $)$.

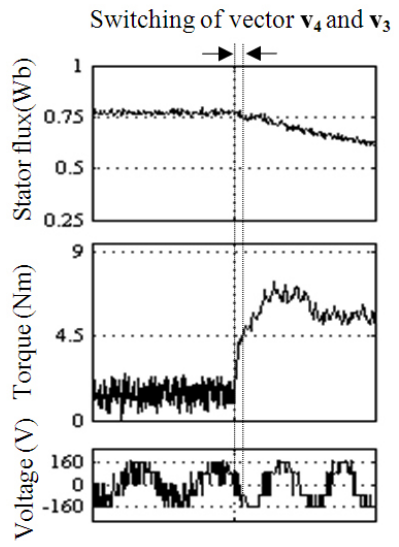

(a)

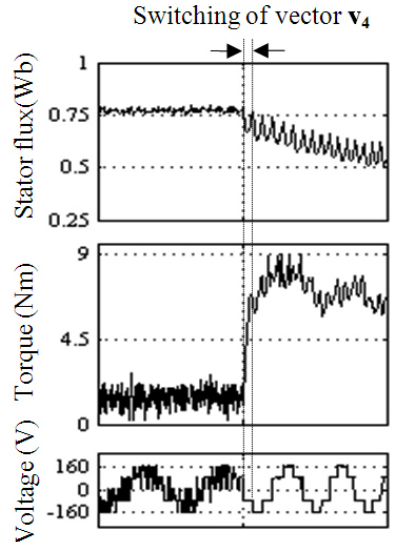

(b)
Fig. 18. Comparison of torque dynamic performance obtained in (a) the basic DTC and (b) the proposed hybrid drive (which is correspond to the results obtained in Fig. 17) (Time Scale: 40ms/div.). due to the optimized voltage vectors selection in controlling simultaneously both the flux and the torque. During a large torque demand, hence a large torque error, the hysteresis torque comparator produces a single status that requires an increase in torque. This means that under this condition, no zero vectors are selected to reduce the torque. At the same time, the flux hysteresis will regulate the flux to follow a circular path using two active voltage vectors. Since no zero voltage vectors are applied, rapid changes in the flux vector position and hence a quick dynamic torque response is achieved. However, this method does not give the fastest dynamic torque response simply because two active voltage vectors are switched during the dynamic condition. In order to achieve the fastest dynamic torque response only a single vector should be switched and held instead of two active voltage vectors.

For the purpose of studying the effect of the voltage vectors on the torque in DTC hysteresis-based drives, the torque equation will be expressed in terms of the stator flux and rotor flux magnitudes as given in (7).

$$
\mathrm{T}_{\mathrm{e}}=\frac{3}{2} \mathrm{P} \frac{\mathrm{L}_{\mathrm{m}}}{\sigma \mathrm{L}_{\mathrm{s}} \mathrm{L}_{\mathrm{r}}} \Psi_{\mathrm{s}} \Psi_{\mathrm{r}} \sin \delta_{\mathrm{sr}}
$$

where $\sigma$ is the total leakage factor and $\delta_{s r}$ is the angle difference between the stator flux and the rotor flux vectors, which plays a vital role in controlling the output torque. The relationship between the rotor flux vector and the stator flux vector in the rotor flux reference frame can be written as:

$$
\Psi_{r}^{r}=\frac{\mathrm{L}_{\mathrm{m}} / \mathrm{L}_{\mathrm{s}}}{1+\mathrm{p} \sigma \tau_{\mathrm{r}}} \Psi_{s}^{r}
$$

where $\tau_{r}$ is the rotor time constant. If the ohmic drop in the stator voltage equation is neglected, then we can approximate the change in the stator flux as:

$$
\Delta \Psi_{s}=v_{s} \Delta \mathrm{t} .
$$

Equation (9) indicates that the instantaneous angular velocity of the stator flux is irregular due to the switching voltage vectors. According to (8), the rotor flux will follow the stator flux, but with the irregular motion removed due to the low pass filtering action.

Fig. 11 shows the space vectors of the stator flux and rotor flux linkages moving in the counterclockwise direction. The motion of the stator flux is dictated by the voltage vectors $\mathbf{v}_{k+1}$ and $\mathbf{v}_{k+2}$. Case 1 is when the stator flux is about to enter sector $\mathrm{k}$ (at $\alpha_{k}=0$ rad.) while case 2 is when the stator flux is about to leave sector $\mathrm{k}$ (at $\alpha_{k}=\pi / 3 \mathrm{rad}$.). The dynamic torque response can be studied by looking at the effects of applying the two voltage vectors on the angle $\Delta \delta_{s r}$. For this purpose, the vectors are redrawn as shown in Fig. 11(b). From Figs.11(a) and (b), it can be seen that $\mathbf{v}_{k+1}$ has a larger tangential component to the circular flux locus, while $\mathbf{v}_{k+2}$ has a larger radial (negative) component in case 1. On the other hand, $\mathbf{v}_{k+1}$ has a larger radial component while $\mathbf{v}_{k+2}$ has a larger tangential component to the circular flux locus in case 2. Fig. 11(b) highlights the effect of selecting different switching states on $\Delta \boldsymbol{\delta}_{s r}$. Based on the continuous rotation of the rotor flux, as opposed to the irregular rotation of the 
stator flux, it can be seen that $\Delta \delta_{s r, 1}$ is larger when $\mathbf{v}_{k+1}$ is switched for case 1 and that $\Delta \delta_{s r, 2}$ is larger when $\mathbf{v}_{k+2}$ is switched for case 2. In fact, if the sector is subdivided into subsectors I and II based on (10), vector $\mathbf{v}_{k+1}$ will result in a larger $\Delta \delta_{s r}$ throughout subsector I and $\mathbf{v}_{k+2}$ will give a larger $\Delta \delta_{s r}$ throughout subsector II.

$$
\begin{array}{ll}
0 \leq \alpha_{\mathrm{k}}<\pi / 6 \mathrm{rad} . & \text { for subsector I } \\
\pi / 6 \leq \alpha_{\mathrm{k}}<\pi / 3 \mathrm{rad} . & \text { for subsector II } .
\end{array}
$$

According to (7), with a larger $\Delta \delta_{s r}, \mathbf{v}_{k+1}$ and $\mathbf{v}_{k+2}$ will give faster dynamic torque responses in subsectors $\mathrm{I}$ and II, respectively. For this reason, the fastest torque dynamic control can be achieved with the proposed hybrid scheme since the optimized active voltage vector, which is determined by $\Psi_{s, \text { mod }}{ }^{-}$, is switched and held (instead of selecting two active voltage vectors) during the torque transient. For example, if a torque dynamic occurs (i.e. the application of a step change in the torque reference) when the flux is in the middle of subsector II, the active voltage $\mathbf{v}_{4}$ is switched and held until the output torque reaches its reference (i.e. $\mathrm{E}_{T e}$ is reduced to zero).

\section{B. Faster motor acceleration}

Theoretically, in a constant flux region, the back-emf will increase when the motor accelerates. Therefore, a larger stator voltage is needed to satisfy the torque demand in accelerating the motor. In the proposed hybrid scheme, whenever the speed dynamic is encountered, as define in part B of Section III, the stator flux locus will be transformed to a hexagonal shape. The torque demand will be naturally fulfilled by the controller, which will gradually drop the applications of the zero-voltage vectors as the speed increases. By transforming the stator flux locus to a hexagonal shape, room will be provided for the stator voltage to increase beyond the hexagonal boundary (overmodulation mode) and the torque demand will naturally transform the stator voltage from PWM to six-step mode [1920]. Since the limit of the stator voltage increases to the sixstep mode (which also increase the limit of the stator flux angular frequency), the constant torque region can be extended and hence results in a higher capability of the torque in a flux weakening region. This, consequently, provides faster motor acceleration.

Note that, the improved capability of the torque in the hybrid scheme uses a speed control loop, where, the reference torque is estimated by a PI controller, as shown in Fig. 9. However, the generation of the reference flux is slightly different when compared to the conventional method [21], where the flux magnitude has a step reduction of $13.4 \%$ as the motor speed reaches its reference $\left(\omega_{m, 2}\right)$. This reduction is to ensure that the output torque can be well-regulated to its reference with the proper level of flux reference as reported in [22]. The reference of flux (for flux weakening operation) is given by:

$$
\Psi_{\mathrm{s}, \text { ref }}=\Psi_{\mathrm{s}, \text { rated }} \frac{\omega_{\text {base,hex }}}{\omega_{\mathrm{m}}}(1-\alpha \cdot \cos (\pi / 6))
$$

where $\Psi_{\text {s,rated }}$ is the rated stator flux, $\omega_{\text {base,hex }}$ is the base speed of the hybrid scheme, $\omega_{m}$ is the motor speed and
TABLE I

DTC-HYSTERESIS BASED AND HYBRID SYSTEMS AND INDUCTION MACHINE PARAMETERS

\begin{tabular}{|l|l|}
\hline \multicolumn{2}{|l|}{ Induction machine } \\
\hline Rated power & $1.5 \mathrm{~kW}$ \\
\hline Rated voltage & $400 \mathrm{~V}$ \\
\hline Rated current & $3.39 \mathrm{~A}$ \\
\hline Rated speed & $1410 \mathrm{rpm}$ \\
\hline Rated torque & $9 \mathrm{Nm}$ \\
\hline Rated flux & $0.892 \mathrm{~Wb}$ \\
\hline Stator resistance & 5.5 \\
\hline Rotor resistance & 4.51 \\
\hline Stator self inductance & $306.5 \mathrm{mH}$ \\
\hline Rotor self inductance & $306.5 \mathrm{mH}$ \\
\hline Mutual inductance & $291.9 \mathrm{mH}$ \\
\hline Number of poles & 4 \\
\hline $\begin{array}{l}\text { DTC-Hysteresis based or Hy- } \\
\text { brid System }\end{array}$ \\
\hline Flux hysteresis band, HB & $0.045 \mathrm{~Wb}$ \\
\hline Torque hysteresis band, $\mathrm{HB}$ \\
\hline DC link voltage, $\mathrm{V}_{d c}$ & $0.9 \mathrm{Nm}$ \\
\hline
\end{tabular}

$\alpha$ is used to activate the step reduction. That is, $\alpha$ is set to 1 when the motor speed reaches its target; otherwise it is 0 . For convenience sake, an illustration on how the flux reference is produced during motor acceleration, for both the conventional DTC and the proposed hybrid scheme, is shown in Fig. 12. The basic DTC uses the conventional flux weakening method, where the variation of the reference flux is inversely proportional to the motor speed [21]. Note that, the base speed for each scheme is defined as the maximum speed at which the maximum torque can be retained under the rated flux condition.

\section{IMPLEMENTATION AND EXPERIMENTAL RESULTS}

The feasibility of the proposed hybrid scheme in achieving excellent dynamic performances is verified through experimentation and comparison with the conventional DTC scheme. The parameters for both schemes and the actual parameters of an induction motor are as shown in Table I. The experimental set-up consists of an IGBT inverter and a $1.5 \mathrm{~kW}$, four-pole squirrel cage induction motor. For safety reasons, the DC voltage was limited to $240 \mathrm{~V}$, which means that the base speed is reduced to $570 \mathrm{rpm}$. It should be noted that using a higher DC voltage would further enhance the torque response since a higher DC voltage will result in a higher rate of change of torque. The control algorithm is implemented on a DSPACE 1102 and an Altera FPGA (APEX20KE). The sampling period of the DTC scheme and the proposed hybrid scheme is $55 \mu \mathrm{s}$.

The torque dynamic control is performed by applying a step change in the reference torque from $1.5 \mathrm{Nm}$ to $9.0 \mathrm{Nm}$ when the flux is in the middle of sector II (i.e. at point $a$ as defined in Fig. 6 (a)). The experimental results under this condition for each scheme are shown in Fig. 13. It can be seen that for the conventional DTC scheme, two active voltage vectors are selected during the torque dynamic. This is indicated by the flux error status waveform which switches between 1 and 0 . For the proposed hybrid scheme, the single flux error status is held. Therefore, only a single vector is selected during the torque dynamic. The selected voltage vector, as discussed in the previous section, provides the fastest torque response. The effect of the proposed selection voltage on the stator flux locus 
can be seen from the experimental results, as shown in Fig. 14 As the torque dynamic occurs in the middle of sector II, the single voltage vector that produces the fastest torque response is selected (i.e. $\mathbf{v}_{4}$ ). This vector also decreases the flux causing the flux locus to momentarily deviate from a circular locus, as shown in Fig. 14.

Fig. 15 compares the output torque capability obtained with the conventional DTC and the proposed hybrid scheme, when a step change in the reference speed is applied from $0.5 \mathrm{p} . \mathrm{u}$ to 2.8 p.u. Note that the per unit (p.u) of speed is defined as $\omega_{m} / \omega_{\text {base }}$, where $\omega_{\text {base }}$ is the base speed of the conventional DTC scheme. From Fig. 15, it can be seen that the capability of the output torque in the proposed hybrid scheme is higher and hence gives faster motor acceleration. It can also be seen that the hybrid scheme provides an extension of the constant torque region and allows the stator voltage to operate in the complete six-step mode, particularly in a flux weakening region (as can be seen in the zoomed image). Fig. 16 highlights the locus of the stator flux for the conventional DTC and the proposed hybrid scheme and corresponds to the results obtained in Fig. 15 .

Fig. 17 compares the output torque capability obtained with both schemes when the motor speed is subjected to a change from 1.25 p.u. to 2.33 p.u. (in a flux weakening region). Obviously, a higher capability of the torque and less acceleration time (i.e. $\Delta \mathrm{t}_{r r, 2}<\Delta \mathrm{t}_{r r, 1}$ ) is achieved in the proposed hybrid scheme. Moreover, the proposed hybrid scheme is able to produce the fastest torque dynamic response with the complete six-step mode operation in a flux weakening region, as shown in Fig. 18.

\section{CONCLUSIONS}

A hybrid scheme for high performance motor control manages to perform in dual-mode operation. The mode control of a circular flux locus is utilized to get proper current regulation during steady state conditions. Conversely, the mode control of a hexagonal flux locus is employed to achieve excellent dynamic performance. By controlling the locus flux into a hexagonal shape, the DTC can be operated in the overmodulation mode up to the complete six-step voltage. The main benefit of the proposed hybrid scheme is its simplicity, since the overmodulation mode can be performed without the needs to estimate the reference voltage, unlike the DTC-SVM approach.

\section{ACKNOWLEDGMENT}

The authors would like to thank the Ministry of Higher Education (MOHE) of the Malaysian government, the Universiti Teknikal Malaysia Melaka (UTeM) and the Universiti Teknologi Malaysia (UTM) for providing the funding and sponsorship for this research.

\section{REFERENCES}

[1] I. Takahashi and T. Noguchi, "A new quick-response and high-efficiency control strategy of an induction motor," IEEE Trans. Ind. Appl., Vol. IA22, pp. 820-827, Sep. 1986.
[2] T. Noguchi, M. Yamamoto, S. Kondo, and I. Takahashi, "Enlarging switching frequency in direct torque-controlled inverter by means of dithering," IEEE Trans. Ind. Appl., Vol. 35, pp. 1358-1366, Nov./Dec. 1999.

[3] S. Mir and M. E. Elbuluk, "Precision torque control in inverter-fed induction machines using fuzzy logic," in Power Electronics Specialists Conference, 1995. PESC '95 Record., 26th Annual IEEE, pp. 396-401, Vol. 1, 1995.

[4] J.-K. Kang and S.-K. Sul, "New direct torque control of induction motor for minimum torque ripple and constant switching frequency," IEEE Trans. Ind. Appl., Vol. 35, No. 5, pp. 1076-1082, Sep./Oct. 1999.

[5] A. Tripathi, A. M. Khambadkone, and S. K. Panda, "Torque ripple analysis and dynamic performance of a space vector modulation based control method for AC-drives," IEEE Tran. Power Electron., Vol. 20, No. 2, pp. 485-492, Mar. 2005.

[6] N. R. N. Idris and A. H. M. Yatim, "Direct torque control of induction machines with constant switching frequency and reduced torque ripple," IEEE Trans. Ind. Electron., Vol. 51, No. 4, pp. 758-767, Aug. 2004.

[7] J. Beerten, J. Verveckken, and J. Driesen, "Predictive Direct Torque Control for Flux and Torque Ripple Reduction," IEEE Trans. Ind. Electron., Vol. 57, No. 1, pp. 404-412, Jan. 2010.

[8] J.-K. Kang, D.-W. Chung, and S.-K. Sul, "Direct torque control of induction machine with variable amplitude control of flux and torque hysteresis bands," in Electric Machines and Drives, International Conference IEMD '99, 1999, pp. 640-642, 1999.

[9] A. Jidin, N. R. N. Idris, A. H. M. Yatim, M. E. Elbuluk, and T. Sutikno, "Extending switching frequency for torque ripple reduction utilizing a constant frequency torque controller in dtc of induction motors," Journal of Power Electronics, Vol. 11, No. 2, pp. 148-155, Mar. 2011.

[10] A. Tripathi, A. M. Khambadkone, and S. K. Panda, "Stator flux based space-vector modulation and closed loop control of the stator flux vector in overmodulation into six-step mode," IEEE Trans. Power Electron., Vol. 19,No. 3, pp. 775-782, May 2004.

[11] C. Lascu, I. Boldea, and F. Blaabjerg, "A modified direct torque control for induction motor sensorless drive," IEEE Trans. Ind. Appl., Vol. 36, No. 1, pp. 122-130, Jan./Feb. 2000.

[12] D. Casadei, G. Serra, and K. Tani, "Implementation of a direct control algorithm for induction motors based on discrete space vector modulation,” IEEE Trans. Power Electron., Vol. 15, No. 4, pp. 769-777, Jul. 2000.

[13] S. Bolognani and M. Zigliotto, "Novel digital continuous control of SVM inverters in the overmodulation range," IEEE Trans. Ind. Appl., Vol. 33, No. 2, pp. 525-530, Mar./ Apr.1997.

[14] A. M. Khambadkone and J. Holtz, "Compensated synchronous PI current controller in overmodulation range and six-step operation of space-vector-modulation-based vector-controlled drives," IEEE Trans. Ind. Electron., Vol. 49, No. 3, pp. 574-580, Jun. 2002.

[15] T. G. Habetler, F. Profumo, M. Pastorelli, and L. M. Tolbert, "Direct torque control of induction machines using space vector modulation," IEEE Trans. Industry Appl., Vol. 28, No. 5, pp. 1045-1053, Sep./ Oct. 1992.

[16] A. Tripathi, A. M. Khambadkone, and S. K. Panda, "Dynamic control of torque in overmodulation and in the field weakening region," IEEE Trans. Power Electron., Vol. 21, No. 4, pp. 1091-1098, Jul. 2006.

[17] G. Griva, T. G. Habetler, F. Profumo, and M. Pastorelli, "Performance evaluation of a direct torque controlled drive in the continuous PWMsquare wave transition region," IEEE Trans. Power Electron., Vol. 10, No. 4, pp. 464-471, Jul. 1995.

[18] M. Depenbrock, "Direct self-control (DSC) of inverter-fed induction machine," IEEE Trans. Power Electron., Vol. 3, No. 4, pp. 420-429, Oct. 1988.

[19] A. Jidin, N. Idris, A. Yatim, and M. Elbuluk, "A novel overmodulation and field weakening strategy for direct torque control of induction machines,' in Industry Applications Society Annual Meeting, IAS '08. IEEE, pp. 1-8, 2008.

[20] A. Jidin, N. R. N. Idris, A. H. M. Yatim, and M. E. Elbuluk, ”A widespeed high torque capability utilizing overmodulation strategy for direct torque control of induction machines," in Energy Conversion Congress and Exposition, ECCE 2009. IEEE, pp. 2757-2762, 2009.

[21] R. Joetten and H. Schierling, "Control of the induction machine in the field weakening range," Proc. IFAC, pp. 297-304, 1983.

[22] X. Xu and D. W. Novotny, "Selection of the flux reference for induction machine drives in the field weakening region," IEEE Trans. Ind. Appl., Vol. 28, No. 6, pp. 1353-1358, Nov./Dec. 1992. 


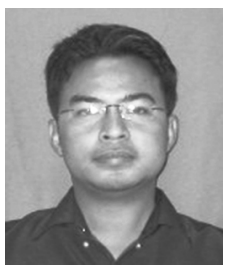

Auzani Jidin received his B.E., M.E. and Ph.D. in Power Electronics and Drives from the Universiti Teknologi Malaysia (UTM), Malaysia, in 2002, 2004 and 2011, respectively. He is currently a Lecturer in the Department of Power Electronics and Drives, Faculty of Electrical Engineering, Universiti Teknikal Malaysia Melaka (UTeM). His research interests include the field of power electronics, motor drive systems, and FPGA and DSP applications.

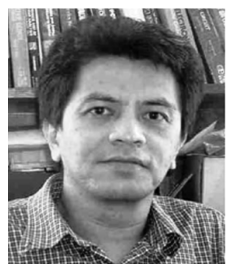

Nik Rumzi Nik Idris received his B.E. in Electrical Engineering from the University of Wollongong, Australia, his M.S. in Power Electronics from Bradford University, West Yorkshire, U.K., and his Ph.D. from the Universiti Teknologi Malaysia (UTM) in 1989, 1993, and 2000, respectively. $\mathrm{He}$ is an Associate Professor at the Universiti Teknologi Malaysia, and an Administrative Committee Member of the Power Electronics, Industrial Electronics, Industrial Applications Joint Chapter of the IEEE Malaysia Section. His research interests include ac drive systems and DSP applications in power electronic systems.

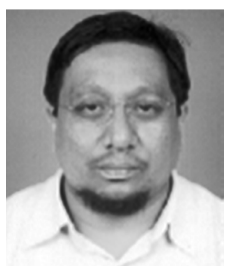

Abdul Halim Mohamed Yatim received his B.S. in Electrical and Electronic Engineering from Portsmouth Polytechnic, Portsmouth, U.K., in 1981, and his M.S. and $\mathrm{Ph} . \mathrm{D}$. in Power Electronics from Bradford University, Bradford, U.K., in 1984 and 1990, respectively. Since 1982, he has been a member of the Faculty of Electrical Engineering at the Universiti Teknologi Malaysia and is currently a Professor and Dean of the Faculty. His current research interests include power quality, renewable/alternative energy, and power electronics applications and drives. He was a Commonwealth Fellow during 1994-1995 at Heriot Watt University, Edinburgh, U.K., and a Visiting Scholar at the Virginia Power Electronics Centre, Virginia Polytechnic Institute and State University, Blacksburg, in 1993. Dr. Yatim is a Fellow of the Institution of Engineers Malaysia and a Registered Professional Engineer with the Malaysian Board of Engineers. He was the first Chapter Chair of the Malaysian Section of the IEEE Power Electronics, Industrial Electronics, Industrial Applications Joint Chapter formed in 2003.

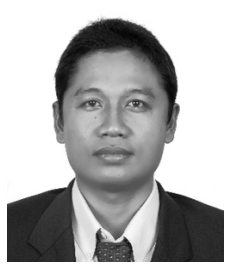

Tole Sutikno received his B.E. and M.E. in Electrical Engineering from Diponegoro University, Indonesia an Gadjah Mada University, Indonesia, in 1999 and 2004, respectively. Since 2001 he has been a Lecturer in Electrical Engineering Department, Universitas Ahmad Dahlan (UAD), Indonesia. Currently, he is pursuing his Ph.D. at the Universiti Teknologi Malaysia (UTM), Malaysia. His research interests include the field of power electronics, motor drive systems and FPGA ap-

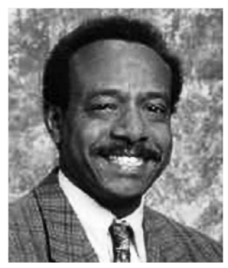

Malik E. Elbuluk received his B.S. (with honors) from the University of Khartoum, Khartoum, Sudan, and his M.S., E.E., and D.S. from the Massachusetts Institute of Technology, Cambridge, in 1976, 1980, 1981, and 1986, respectively, all in Electrical Engineering. He is a Professor at the University of Akron, Akron, $\mathrm{OH}$, where he has been since 1989 . He was with the faculty of the Electrical and Computer Engineering Department and the Electric Power Research Center, North Carolina State University, from 1986 to 1989. He was a Summer Research Fellow at the NASA Lewis Research Center, Cleveland, OH, from 1991 to 2010. His work at NASA included low-temperature electronics for space missions, modeling and simulation of the Space Station Freedom (SSF), the power by wire (PBW), the power electronic building blocks (PEBB), and the starter/generator for aircraft engines and the sensorless control of electromechanical actuators (EMA) for the more electric aircraft (MEA). His teaching and research interests include the area of power electronics, electric machines, control systems, fuzzy logic, and neural networks. Prof. Elbuluk actively publishes and reviews papers for IEEE Conferences and Transactions, and has organized and chaired a number of sessions for the Power Electronics (PE), the Industry Application (IA) and the Industrial Electronics (IE) Societies. He was an Associate Editor for the IEEE Transactions in Power Electronics and was the Manufacturing Systems Development and Applications Department (MSDAD) Vice Chair and then Chair for the IEEE Transactions on Industry Application. He was also the Vice President and Technical Program Chair for the Industry Automation and Control Committee (IACC). He is a Registered Professional Engineer in the State of Ohio. 